\title{
The Efficiency of Rectal Fluid Therapy in Moderately Dehydrated Horses
}

\author{
Patricia AȘTELEAN ${ }^{1}$, Eva DIUGAN ${ }^{2}$, Cristian MOLNAR ${ }^{3}$, Orsolya SÁRPATAKI ${ }^{1}$, Răzvan CODEA ${ }^{1}$, \\ Alexandra I. BLIDARU ${ }^{1}$, Adrian POTARNICHE ${ }^{1}$, Ioan MARCUS ${ }^{1}$, and Bogdan SEVASTRE ${ }^{1 *}$, \\ ${ }^{1}$ University of Agricultural Science and Veterinary Medicine, Faculty of Veterinary Medicine, \\ Manastur Street no. 3-5, 400372, Cluj-Napoca, Romania, \\ ${ }^{2}$ Beclean Horse Stud Farm, Direction for Horse Breading, National Forestry Direction ROMSILVA, \\ Petricani Street, no 9A, 023841, Bucharest, Romania \\ ${ }^{3}$ Cabalosportvet, Viisoara Street, 420006, Bistrita, Romania \\ *corresponding author: bogdan.sevastre@usamvcluj.ro
}

Bulletin UASVM Veterinary Medicine 75(1)/2018

Print ISSN 1843-5270; Electronic ISSN 1843-5378

doi:10.15835/buasvmcn-vm:004917

\begin{abstract}
:
Dehydration and hydro-electrolytic imbalances are relatively common and life threatening conditions in many animal species including horses. In the present study, we highlighted the efficacy of rectal rehydration in horses, nowadays less commonly used. The study was performed on eight non-pregnant mares (Romanian semigreus and Lipițan breeds), from Beclean horse stud farm, affected by mild dehydration. The method consists in rectal administration in the form of a high enema of a balanced polyionic solution by using an esophageal tube; the solution contains water, sodium chloride and potassium chloride. Blood samples were collected on EDTA and procoagulant vacutainers, before and after fluid therapy. Laboratory investigations include complete blood count and electrolytes measurement, total protein, albumin, and creatinine. Expectedly, dehydrated animals shown borderline elevated hematocrit associated with mild relative hyperproteinemia and hypernatremia, and elevated uremia levels. In all cases, the parameters were restored in response to therapy, and no side effects were recorded. In conclusion, this method may be used in mild dehydrated patients, when the animals refuse/cannot drink water.
\end{abstract}

Keywords: dehydration, high enema, horse

\section{Introduction}

Dehydration represents a common emergency in veterinary medicine, it affects a wide range of species. In horse, it can be induced by various factors as painful oral disorders, pharyngeal disorders, neuropathies accomplished by dysphagia (Wilson, 2011), gastroenteritis, gastrointestinal obstructions, nephrotic syndrome, endotoxemia, fever, overheating, strenuous exercises etc. Whatever the cause, dehydration represent a medical emergency, it may easily lead to hypovolemic shock, prerenal kidney insufficiency, inability of core body temperature regulation etc. (Sprayberry and Robbinson, 2015).
In horses, rehydration can be done orally, on intravenous route or via rectum, as enema. Oral rehydration is a convenient method but is recommended for patients with normal, functional digestive tract, the most common route being the intravenous one. (Fielding and Magdesian, 2015). However, if not properly done intravenous rehydration may be responsible for infection, hydro-electrolytic disorders, and volume overload. Rehydration via rectum, by high enema (HE) was commonly used in the past and much rarely nowadays. HE can be used not only in the patients who cannot be rehydrated orally; HE has some certain benefits as compared to intravenous 
route, it does not require sterile solutions and it has lower risk of fluid overload.

In the present study, we investigated the efficiency of rehydration by HE, in mild dehydrated horses. We evaluated each case previously and following the rehydration therapy; the level of dehydration was established by clinical and laboratory criteria including hematology and plasma biochemistry.

\section{Materials and methods}

Animal care and experimental procedures

The present study was performed in the Beclean Horse Stud Farm, Beclean city, BistritaNasaud County, Romania, during May-June, 2017. In the study we included only adult, nonpregnant animals, spontaneously affected by mild dehydration, (approx. 6\% body weight loss), and no able to drink water. The assessment of dehydration level and the decision for rehydration therapy was done, based on clinical and laboratory criteria. An experienced veterinary clinician E.D., took these decisions based on widely accepted guidelines (heart and respiratory rate, capillary refilling time, exophthalmia, color of the mucous membranes, skin fold persistence, packed cell volume, total protein and creatinine level) (Collatos, 1999; Corley and Stephen, 2008; Fielding and Magdesian, 2015). Eight adult non-pregnant mares on which two belong to Lipitan breed and six to Romanian semigreus, in body weight between $510-680 \mathrm{~kg}$ were included in study.

Laboratory analysis. Blood samples were collected before and after the therapy. Complete blood count (CBC) was performed on fresh anticoagulated blood (KEDTA), using Abacus Junior Vet 5 diff, automatic analyzer (Diatron Messtechnik, Budapest, Hungary). For plasma biochemistry the blood was drawn on clot activator vacutainers, later it was centrifuged and serum samples were stored at $-20^{\circ} \mathrm{C}$ until use. Serum chemistry was measured using screen point semiautomatic analyser STAT - FAX 1904 Plus Global Medical Instrumentation Inc. 6511 Bunker Lake Blvd. Ramsey Minnesota, 55303, using special kits and following the producer specifications.

Rehydration therapy was done by HE; the fluid deficit was calculated by multiplying the body weight, by the percent of dehydration (Moore et $a l ., 2011)$. The rehydration was performed with a mixture of salts in demineralized water; $\mathrm{Na}^{+} 135$ $\mathrm{mmol} / \mathrm{L}, \mathrm{K}^{+} 5 \mathrm{mmol} / \mathrm{L}$, and $\mathrm{Cl}^{-} 95 \mathrm{mmol} / \mathrm{L}$ (Reuss, 2014). Before use, the solution was heated up to $37^{\circ} \mathrm{C}$. The enema was done using a well lubricated esophageal tube $10-15 \mathrm{~cm}$ depth, by gravitation force, no more than five liters once.

Bioethics: The study was performed with the approval of the Direction for Horse Breading, National Forestry Direction ROMSILVA (accord no. 11271/Gh.D./28.03.2017) and the approval of the Bioethics and Research Ethics Comity of UASVM Cluj (approval no. 60 /24.05.2017). This clinical study was done following the Good Veterinary Practice guidelines, all the animals received the adequate therapy, provided by qualified veterinarians. Blood samples collected into the present study, have had primary the diagnostic purpose, and secondly the evaluation of the therapeutically efficiency. Later, the samples were subject to supplementary analysis required by the protocol, but the patients undergo no additionally medical procedures.

\section{Statistical analysis}

All data are reported as the mean \pm SEM. The Gaussian distribution was checked by the D’Agostino and Pearson omnibus normality test. The differences between initial and final values were checked by two tailed, paired T Student test, followed by Welch correction. Statistical significance was at $\mathrm{p}<0.05 \quad(95 \%$ confidence interval). Statistical values and figures were obtained using GraphPad Prism version 5.0 for Windows, GraphPad Software, San Diego California USA.

\section{Results and discussions}

Rehydration by HE had no adverse reactions or accidents. The clinical and laboratory data were analyzed by comparing the clinical and laboratory status both previous, and post therapy. The animals included in study showed clinical signs of mild dehydration (approx. 6\%). They revealed slightly elevated heart rate $52.12 \pm 4.61$ beats/ min, elevated respiratory rate $23.62 \pm 1.59$ breads / min, slightly prolonged capillary refilling time, skin fold persistence was not affected. The mucous membranes were normal, and enophthalmia was not present. The therapy reduced the heart rate to $39.25 \pm 3.84$ beats $/ \mathrm{min}(\mathrm{p}>0.05)$ and respiratory rate to $14.25 \pm 1.98$ beats $/ \mathrm{min}(\mathrm{p}>0.001)$. 

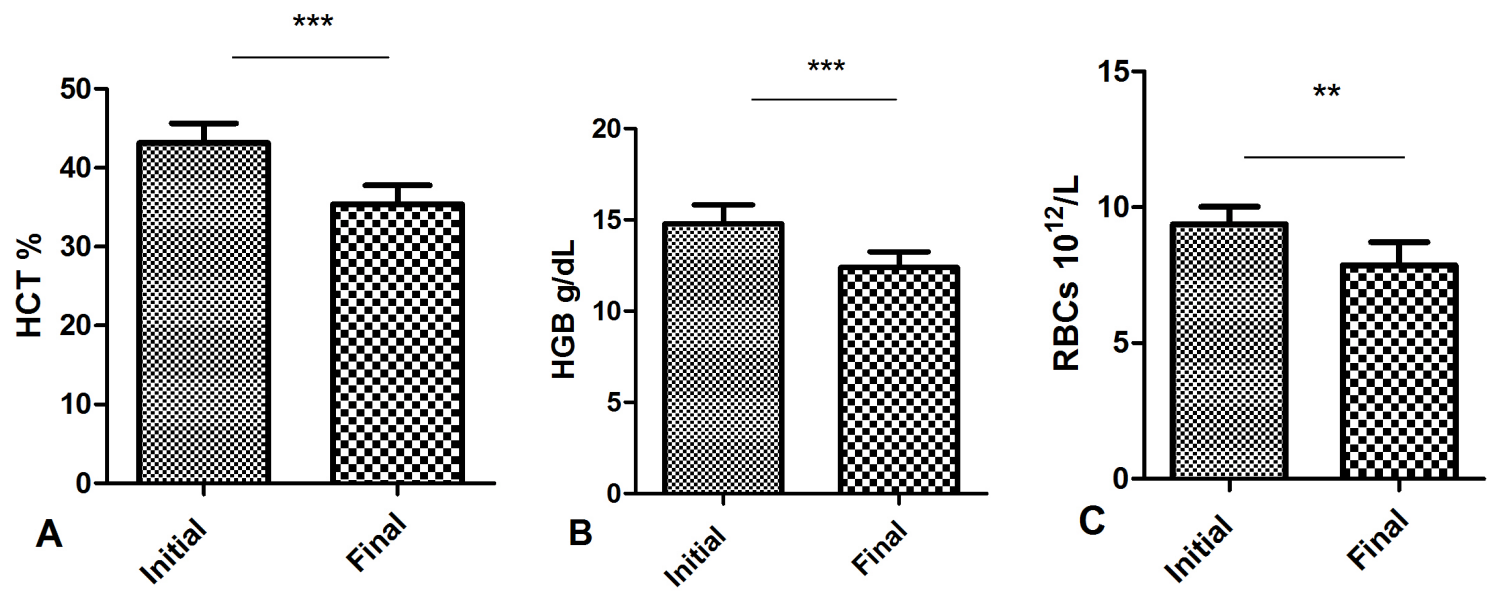

Figure 1. Erythrogram before and after the rehydration therapy, hematocrite (HCT) (\%) (A), hemoglobin (HGB) (g/dL) (B), and red blood cells (RBCs) $\left(10^{12} / \mathrm{L}\right)(\mathrm{C})$ $\left.C^{*}=\mathrm{p}>0.05,{ }^{* *}=\mathrm{p}>0.01,{ }^{* * *}=\mathrm{p}>0.001\right) .($ mean \pm SEM $)(8$ animals $/$ group $)$

Table 1. The effect of high enema on the mean corpuscular volume (MCV), mean corpuscular hemoglobin (MCH), mean corpuscular hemoglobin concentration (MCHC) and red blood cell deviation width (RDWcv) (mean \pm S.E.M.) $\left(10^{9}\right.$ cells/L)

\begin{tabular}{ccccc}
\hline & MCV (fL) & MCH (pg) & MCHC (g/dL) & RDWcv (\%) \\
\hline Initial & $46.06 \pm 2 ., 56$ & $17.79 \pm 1 ., 61$ & $34.30 \pm 1.17$ & $22.53 \pm 0.85$ \\
\hline Final & $45.10 \pm 2.15$ & $18.22 \pm 1.82$ & $35.39 \pm 0.74$ & $22.18 \pm 0.90$ \\
\hline
\end{tabular}
S.E.M = Standard Error of the Mean (8 animals / group)

Normal values: MCV 41-49 fl; MCH 13-18 pg; MCHC 31-37 g/dl; RDW 17-20\% (Knottenbelt and Southwood)

Table 2. The effect of high enema on the platelet number (PLT), plateletocrite (PCT), mean platelet volume (MPV) and platelet deviation width (PDW) (mean \pm S.E.M.)

\begin{tabular}{ccccc}
\hline & PLT $(\mathbf{1 0} / \mathbf{L})$ & PCT $(\%)$ & MPV (fL) & PDWcv (\%) \\
\hline Initial & $127.12 \pm 52.04$ & $0.10 \pm 0.04$ & $7.88 \pm 0.60$ & $37.61 \pm 1.73$ \\
\hline Final & $120.07 \pm 29.07$ & $0.10 \pm 0.01$ & $7.88 \pm 0.79$ & $37.18 \pm 2.77$ \\
\hline SFE
\end{tabular}

S.E.M = Standard Error of the Mean (8 animals / group)

Normal values: PLT 100-550 x 10\%/L; PCT 0,07-0,21\%; MPV 5,4-9,3 fl; PDWcv 24-72\% (Knottenbelt and Southwood)

Dehydration influenced also the erythrogram, HCT was elevated up to the higher level of normal range ( $43.12 \pm 2.53 \%$ ), accomplished by elevated red blood cells count (RBCs) $9.38 \pm 0,64$ $10^{12} / \mathrm{L}$ and hemoglobin (HGB) was $14.79 \pm 1.02 \mathrm{~g} /$ dL. Rehydration therapy reduced the hematocrit (HCT) up to $35.37 \pm 2.38 \%$ ( $>0.001)$, RBCs to $7.87 \pm 0.8410^{12} / \mathrm{L}(\mathrm{p}>0.01)$, and HGB $12.39 \pm 0.87$ $\mathrm{g} / \mathrm{dL}(\mathrm{p}>0.001)$ (Fig. 1.). Red blood cells indices showed no changes (Tab. 1.), while platelets remained confined within normal limits without significant changes either (Tab. 2.).

The therapy induced mild mature leukocytosis with neutrophilia and lymphocytosis, which represent classic features of excitement response leukogram (Table 3.).

Dehydration leaded to moderate elevation of $\mathrm{Na}^{+}$ions (145.65 $\left.\pm 4.18 \mathrm{mmol} / \mathrm{L}\right)$ and $\mathrm{Cl}^{-}$ $(117.63 \pm 8.80 \mathrm{mmol} / \mathrm{L})$. They were restored to normal in response to therapy, $\mathrm{Na}^{+}$ions $(138.74$ 
Table 3. The effect of high enema on tthe WBC count and differential count (mean \pm S.E.M.) $\left(10^{9}\right.$ cells/L)

\begin{tabular}{ccccccc}
\hline Group & WBCs & $\mathbf{N}$ & $\mathbf{E}$ & $\mathbf{B}$ & $\mathbf{L}$ & M \\
\hline Initial & $6.83 \pm 1.23$ & $3.56 \pm 1.21$ & $0.31 \pm 0.15$ & $0.03 \pm 0.02$ & $2.63 \pm 1.03$ & $0.29 \pm 0.22$ \\
\hline Final & $8.41 \pm 1.93$ & $4.73 \pm 1.63$ & $0.23 \pm 0.16$ & $0.02 \pm 0.007$ & $3.12 \pm 1.20$ & $0.30 \pm 0.26$ \\
\hline S.E.M = Standard Error of the Mean (8 animals / group)
\end{tabular}

WBCs - White blood cells, N - Neutrophils, E - Eosinophil's, B - Basophiles, L - Lymphocytes, M - Monocytes

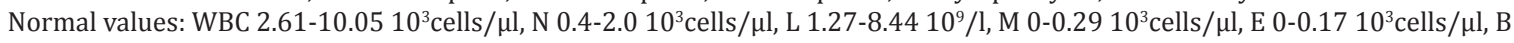
0-0.02 $10^{3} \mathrm{cells} / \mu \mathrm{l}$ (Knottenbelt and Southwood)
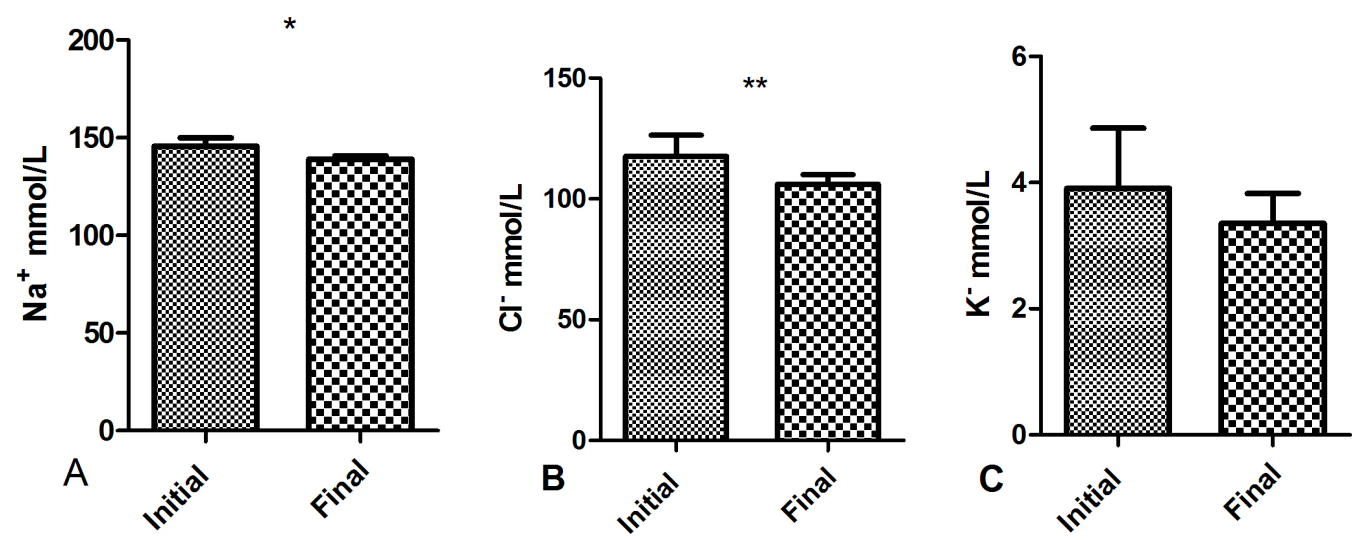

Figure 2. Plasma ions before and after the rehydration therapy, sodium $\left(\mathrm{Na}^{+}\right)(\mathrm{mmol} / \mathrm{L})(\mathrm{A})$, chloride $\left(\mathrm{Cl}^{-}\right)(\mathrm{mmol} / \mathrm{L})(\mathrm{B})$, and potassium $\left(\mathrm{K}^{+}\right)(\mathrm{mmol} / \mathrm{L})(\mathrm{C})$

Normal values: $\mathrm{Na}^{+} 134-143 \mathrm{mmol} / \mathrm{L}, \mathrm{C}^{\mathrm{l}}-90-105 \mathrm{mmol} / \mathrm{L}, \mathrm{K}^{+}-3.5-5.5 \mathrm{mmol} / \mathrm{L}$ (Knottenbelt and Southwood) $\left.C^{*}=p>0.05,{ }^{* *}=p>0.01\right) .($ mean \pm SEM $)(8$ animals / group $)$

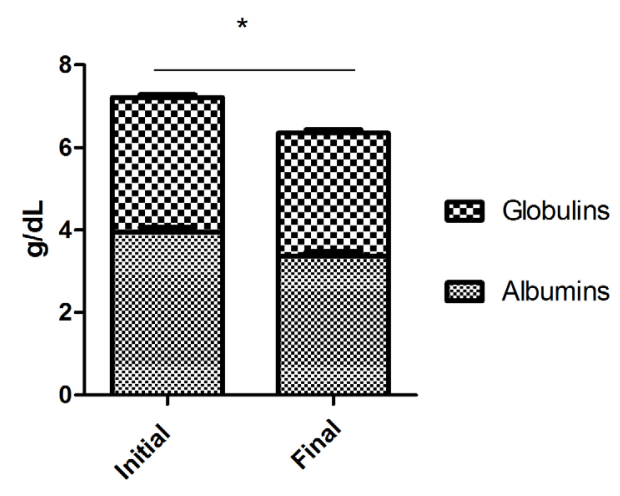

Figure 3. Plasma proteins before and after the rehydration therapy, $(\mathrm{g} / \mathrm{dL})$ $\left.C^{*}=\mathrm{p}>0.05\right)($ mean \pm SEM) $(8$ animals / group)

$\pm 5.19 \mathrm{mmol} / \mathrm{L})(\mathrm{p}<0.05)$ and $\mathrm{Cl}^{-}(106.01 \pm 4.03$ $\mathrm{mmol} / \mathrm{L})(\mathrm{p}<0.01)$. Despite some isolated cases who showed hyperkalemia, the average potassium levels remained within normal range (3.90 \pm $0.95 \mathrm{mmol} / \mathrm{L})$, thus therapy had no significant influence ( $3.35 \pm 0.47 \mathrm{mmol} / \mathrm{L})(\mathrm{p}>0.05)$ (Fig. 2.). Relative hyperproteinemia was another feature of biochemical profile in dehydrated horses, both
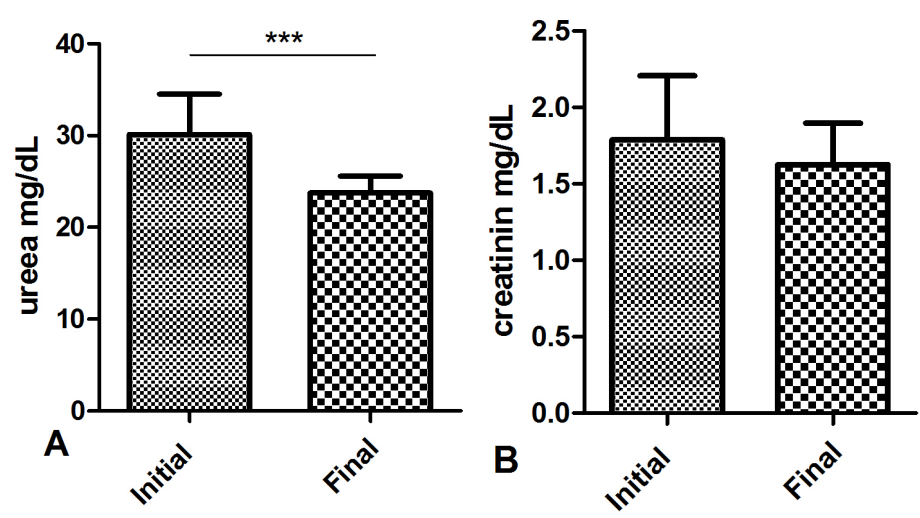

Figure 4. Plasma urea $(\mathrm{mg} / \mathrm{dL})(\mathrm{A})$ and creatinine $(\mathrm{mg} / \mathrm{dL})(\mathrm{B})$ Normal values: Urea 11-27 mg/dl, Creatinine 0.4-2.2 mg/dl (Knottenbelt and Southwood)

$\left(^{* *+}=\mathrm{p}>0.001\right) \cdot($ mean \pm SEM $)(8$ animals $/$ group $)$

albumin $(3.95 \pm 0.31 \mathrm{~g} / \mathrm{dL})$ and globulin $(3.35 \pm$ $0.11 \mathrm{~g} / \mathrm{dL}$ ) levels being proportionally increased (albumin/ globulin ratio remained unchanged $1.21 \pm 0.10$ ). They drop to normal level in response the rehydration $(3.37 \pm 0.29$ and respectively 2.97 $\pm 0.23 \mathrm{~g} / \mathrm{dL}$ ).

Dehydration had also as side effect the prerenal kidney failure manifested by elevated 
urea levels (30.75 $\pm 3.65 \mathrm{mg} / \mathrm{dL})$, while creatinine was inconstantly increased $(1.78 \pm 0.41 \mathrm{mg} / \mathrm{dL})$. They drop back to normal in response to therapy, urea $23.75 \pm 1.83 \mathrm{mg} / \mathrm{dL}(\mathrm{p}<0.001)$, and creatinine $1.62 \pm 0.27 \mathrm{mg} / \mathrm{dL}(\mathrm{p}>0.05)$.

Rehydration by HE is a reliable therapy not only when oral therapy is not possible of it is no venous access for intravenous route. Rectal mucosa is permeable to fluids as well as for various drugs (Girisgin et. al., 2005). In horses, HE has also other advantages, relevant especially in farm condition. It does not require special monitoring equipment's, and neither sterile rehydration fluids. The risks are also significantly lower as compared to oral or intravenous fluid replacement therapy (Sprayberry and Robbinson, 2015). However, there are few studies about the efficiency of HE in severe dehydrated patients, or those affected by hypovolemic shock.

We are fully aware that our conclusion are limited by a relative small number of cases, however they highlight the efficiency of HE at least in horses affected by mild dehydration. The efficiency of the therapy was manifested by the improvement of clinical parameters, hematological profile and plasma biochemistry. Notably, no accidents or any side effects were recorded. Thus, rehydration by high enema might be considered in cases affected by mild dehydration, anytime when voluntary water consumption is not possible.

Acknowledgments: We kindly acknowledge Mr. Ing. Gheorghe Dima, the Head of Direction for Horse Breading, National Forestry Direction ROMSILVA, for approval our study, as well as the Beclean Stud Farm management team.

Declaration of interests: The authors report no conflict of interest.

\section{References}

1. Brownlow MA, Hutchins DR (1982). The concept of osmolality: Its use in the evaluation of "dehydration" in the horse. Equine vet J Suppl, 14: 106-110.

2. Butudom P, Axiak SM, Nielsen BD, Eberhart SW, Schott II HC (2003). Effect of varying initial drink volume on rehydration of horses. Physiol Behav, 79: 135-142.

3. Collatos C (1999). Fluid therapy: When and where? American Association of Equine Practitioners AAEP proceedings, vol. 45 .

4. Corley K, Stephen J (2008). The equine hospital manual. Oxford: Blackwell (pp. 293-294).

5. Fielding CL, Magdesian KG (2015). Equine fluid therapy. Ames: Wiley-Blackwood, (pp. 152-154, 261-276).

6. Franklin PR (2012). Equine Medicine Field Tactics 103: Procedures and Therapies for Fluid Therapy. Annual Resort Symposium of the American Association of Equine Practitioners AAEP.

7. Girisgin AS, Acar F, Cander B, Gul M, Kocak S, Bodur S (2006). Fluid replacement via the rectum for treatment of hypovolaemic shock in an animal model. Emerg Med J., 23: 862-864.

8. Knottenbelt DC, Malalana F (2015). Equine formulary. (2nd ed.). Oxford: Saunders, (pp. 7-12).

9. Moore RM (2009). Medical treatment of horses with colic, 11th International Congress of the World Equine Veterinary Association.

10. Rose RJ, Hodgson DR (2000). Fluid and electrolyte therapy: Assessment of fluid and electrolyte balance. In: R. J. Rose \& D. R. Hodgson (Eds.), Manual of Equine Practice (2nd ed.) (pp. 757-758). Philadelphia: Saunders.

11. Sprayberry KA, Robinsons EN (2015). Robbinson's Current Therapy in Equine Medicine. (7th Edition). St. Louis: Saunders, (pp. 901-903).

12. Wilson D (2011). Clinically veterinary adviser- the horse. Philadelphia: Saunders, (pp. 139-140). 